\title{
Computerized dynamic fluid simulation (CFD) for measuring the influence of the cab deflector on the aerodynamics of trucks
}

\author{
Sergiu Lazăr ${ }^{1}$ \\ ${ }^{1}$ Faculty of Engineering, Lucian Blaga University of Sibiu, Sibiu, Romania \\ E-mail: sergiu.lazar@ulbsibiu.ro
}

\begin{abstract}
This paper refers to how the cab deflector of trucks can influence the aerodynamic coefficient. The first part of the paper includes some generalities taken from previous studies, regarding the types of solutions to improve aerodynamics for trucks. The second part of the paper is a more practical one and has two main chapters: modeling and simulation of modeled parts. In this sense, a truck and 3 cabin deflectors were schematically modeled in Catia v5. After assembly in the Catia v5 program, the impact of the cabin deflector was analyzed. Thus, a computerized dynamic fluid simulation (CFD) was performed using the specific module in Ansys. The simulation included the CFD analysis of the four possible variants: truck without deflector, truck + deflector 1 , truck + deflector 2 , truck + deflector 3 . All mentioned variants were analyzed at 3 different speeds: $50 \mathrm{~km} / \mathrm{h}, 70 \mathrm{~km} / \mathrm{h}$ and $90 \mathrm{~km} /$. This analysis revealed information on the efficiency of each deflector, the value of the pressure as well as the most affected areas, the value of the turbulent kinetic energy, the value of the drag force and the aerodynamic coefficient.
\end{abstract}

Keywords: CFD Analysis, cab deflector, aerodynamics improvement.

\section{Introduction}

There are currently many solutions proposed to improve the aerodynamics of vehicles. The decrease in the aerodynamic coefficient is strictly related to two other relevant aspects: the reduction of fuel consumption and the reduction of the negative impact on the environment. For trucks, aerodynamic elements can be introduced for both the cab and the trailer. The most effective solutions are considered by some researchers in the field as the installation of the cab or trailer deflector.

With budgets tight, gas prices on the rise, and fuel economy on everyone's mind, it is now more imperative than ever to invest in new energy-saving technologies among all products and services, including more energy efficient vehicles. In the automotive industry, trucks are known for their relatively higher drag coefficients which suggest that there is room for improvement. [1]

Previous studies show that the efficiency of the cabin deflectors is between 11 and 20\%. [1] [2]

\section{Aerodynamic Drag Calculation}

Drag is the force of wind or air resistance pushing in the opposite direction to the motion of the object. The drag coefficient $\left(\mathrm{C}_{\mathrm{x}}\right)$ is useful when comparing the aerodynamic efficiency between different vehicles [5]. It is related to the aerodynamic drag force $\left(\mathrm{R}_{\mathrm{a}}\right)$, vehicle speed $\left(\mathrm{v}_{\mathrm{x}}\right)$, frontal area $(A)$ and the density $(\rho)$ and is defined by: 


$$
R_{a}=\frac{1}{2} \cdot \rho \cdot C_{x} \cdot v_{x}^{2} \cdot \mathrm{A}
$$

The drag force depends on the four parameters:

- $\quad$ air density $\rho=1.225 \mathrm{~kg} / \mathrm{m}^{3}$;

- drag coefficient, $\mathrm{Cx}$;

- vehicle speed, $\mathrm{v}_{\mathrm{x}}$

- frontal area, A.

Air-resistant power on the frontal area:

$$
P_{a}[\mathrm{~W}]=R_{a}[\mathrm{~N}] \cdot \mathbf{v}[\mathrm{m} / \mathrm{s}]
$$

Basically, the air resistance has three directions on which it can act on the car: longitudinal (x), lateral (y) and vertical axis (z). The component with significant effect is on the longitudinal axis (x) in the direction of travel of the vehicle.

Each axis corresponds to an aerodynamic coefficient $\left(\mathrm{C}_{\mathrm{x}}, \mathrm{C}_{\mathrm{y}}\right.$ and $\left.\mathrm{C}_{\mathrm{z}}\right)$. As the car moves in the direction of the longitudinal axis, the air resistance coefficient for this axis will be denoted by $\mathrm{C}_{\mathrm{x}}, \mathrm{x}$ being the longitudinal axis.

From the expression of the resistance force of the air, it appears that there are 3 parameters: the aerodynamic coefficient $\left(C_{x}\right)$, the area of the maximum transverse velocity $(A)$ The first two parameters $\left(\mathrm{C}_{\mathrm{x}}\right.$ and $\left.\mathrm{A}\right)$ are consistent and depend on the shape of the body.

The ideal shape from an aerodynamic point of view is like a drop of water. The $C_{x}$ of this shape is only 0.04 . The more a car owns this shape, the lower the drag force.
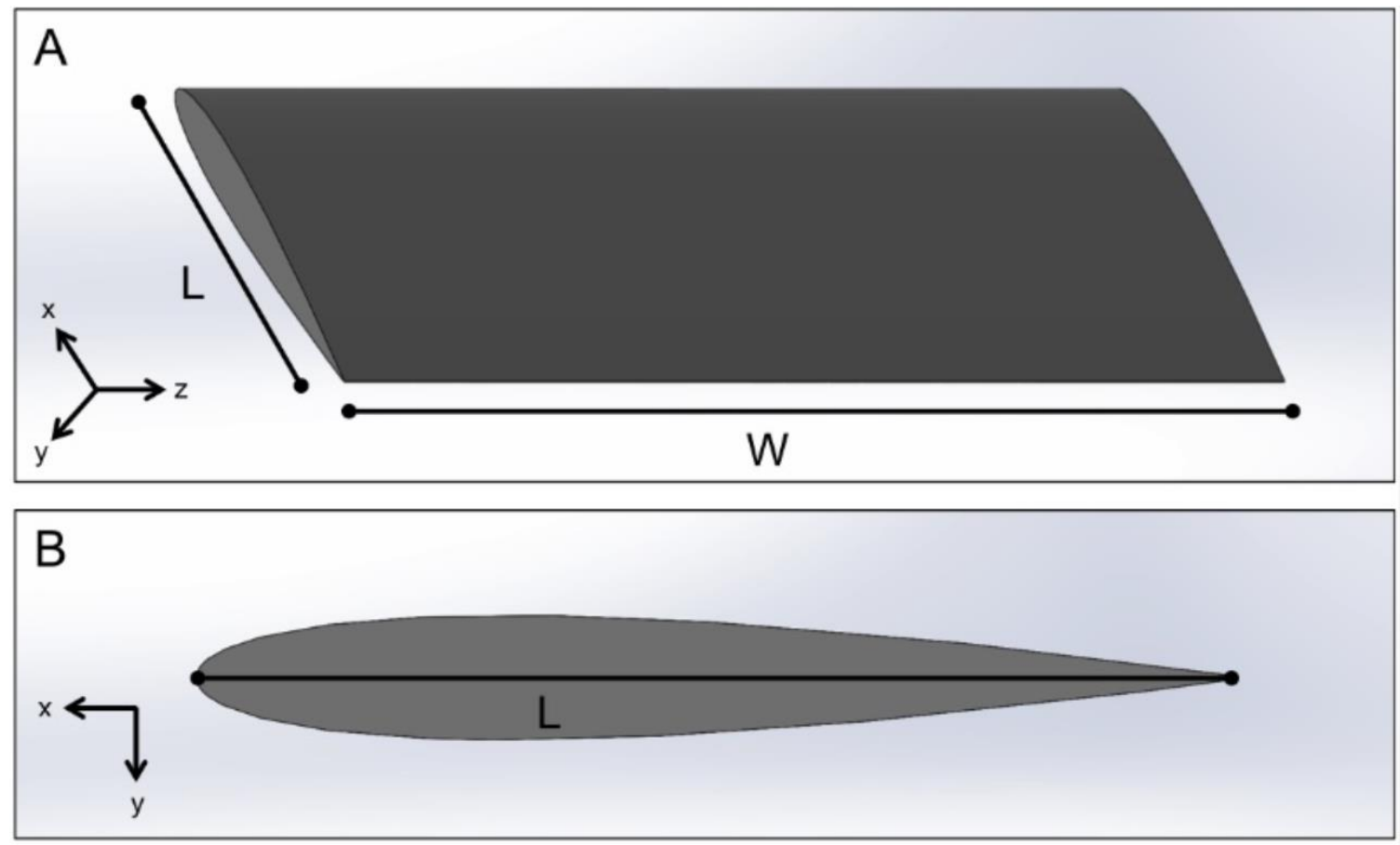

Figure 1. The ideal aerodynamic shape [3] 


\section{Mechanical design and CFD analysis}

The three-dimensional modeling of the elements was done through the Catia v5 design program - the academic version. The mechanical design was made by means of Pad and Pocket operations, of the previously made sketches. The following were designed in turn: the cab (without details inside), the trailer, the running system, the chassis and the auxiliary elements. Then, we proceeded to design 3 cabin deflectors with different geometries.

The computational fluid dynamics (CFD) technique is utilized to the analysis of air flow around this device and also to optimize the geometry of device that has important effect on drag reduction. [4] I performed the CFD analysis through the Ansys program.

\section{D Modelling of truck}
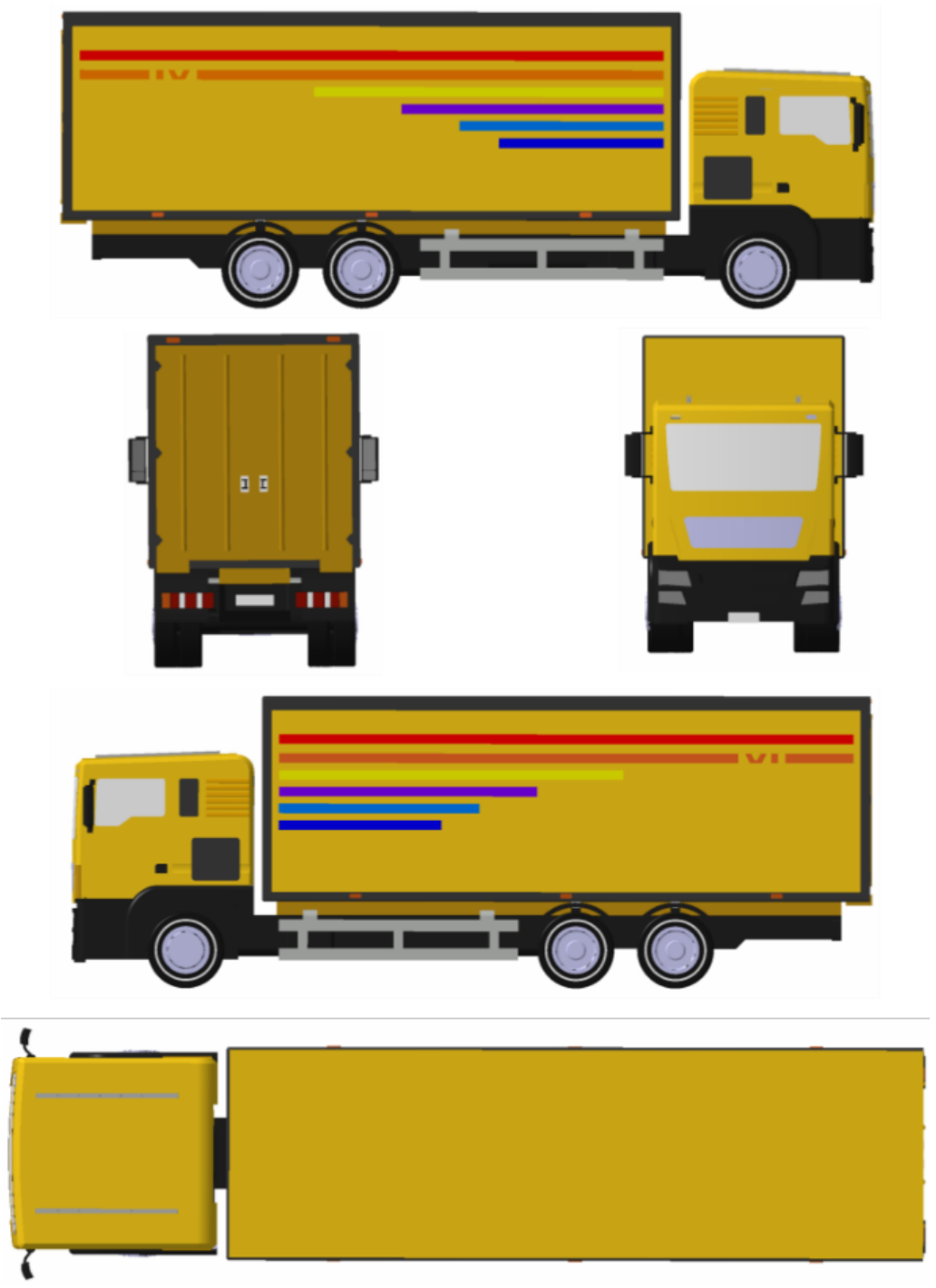

Figure 2. The designed truck to be analysed 
Volume 3, Issue 1, 2021

ISSN: 2668-0416

Thoth Publishing House

3D Modelling of cab deflectors
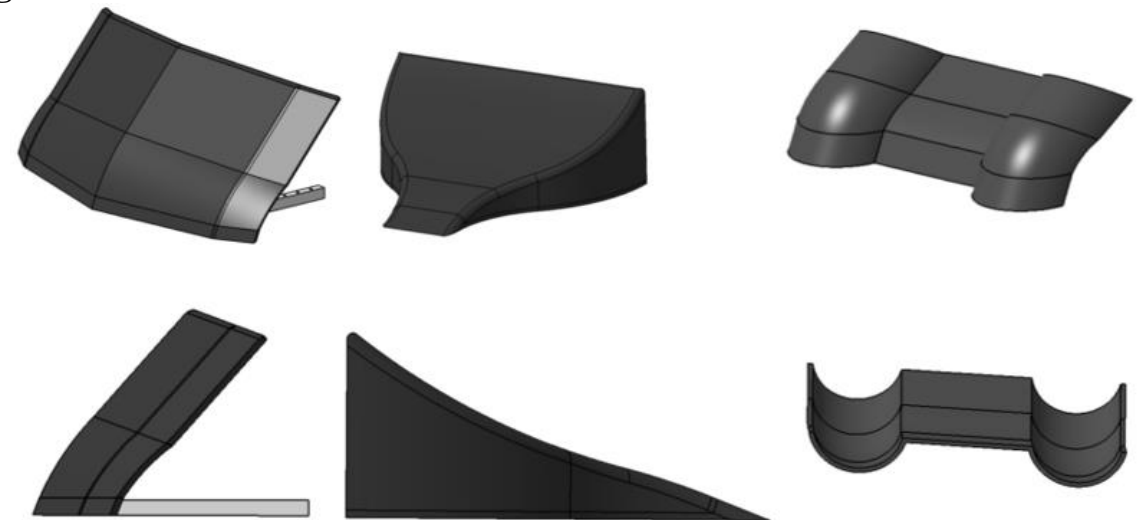

Figure 3. The designed deflectors to be analysed

\section{CFD analysis}

- Without cab deflector

Table 1. Velocity, pressure and turbulent kinetic energy for truck without cab deflector

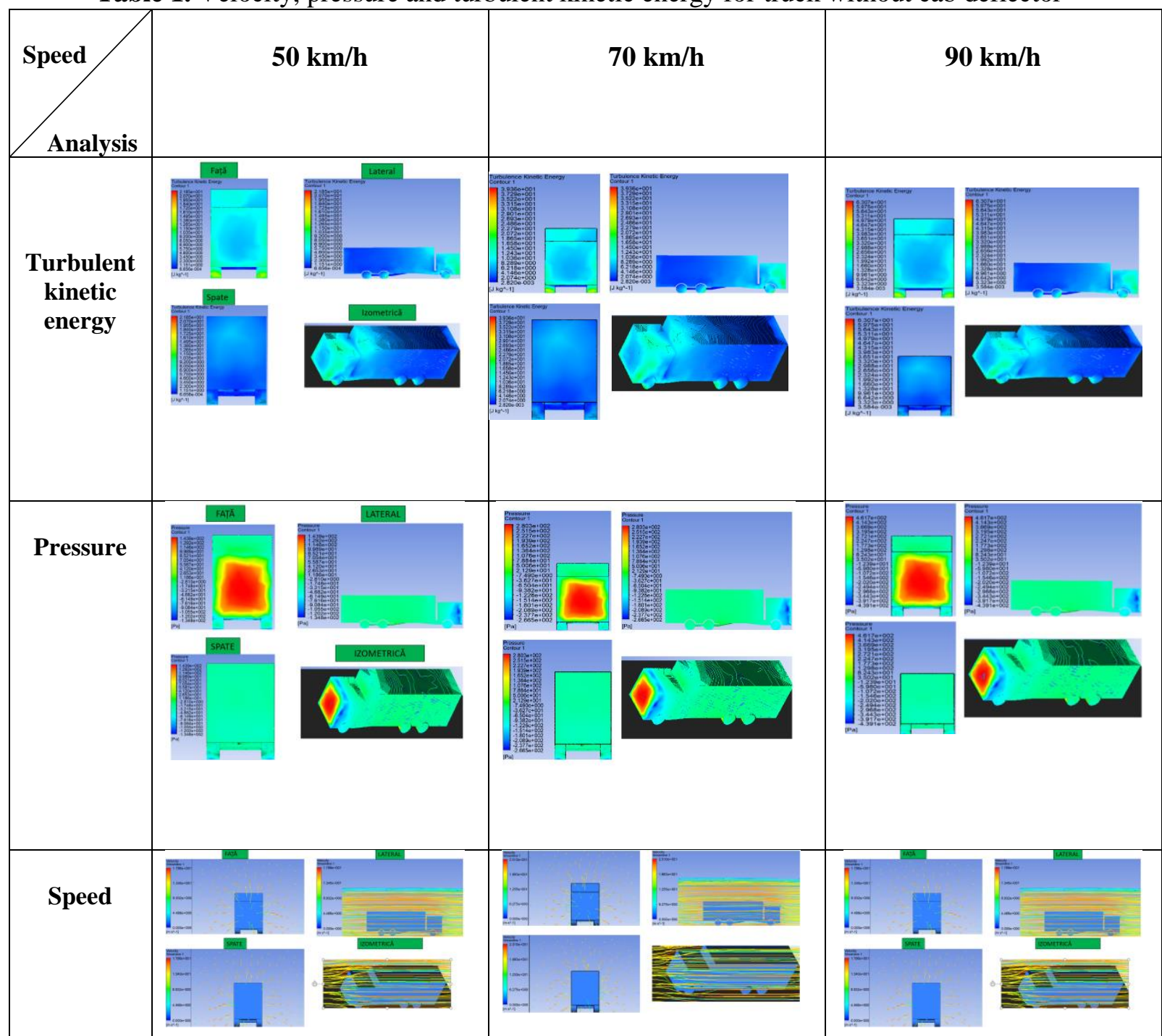


Volume 3, Issue 1, 2021

ISSN: 2668-0416

Thoth Publishing House

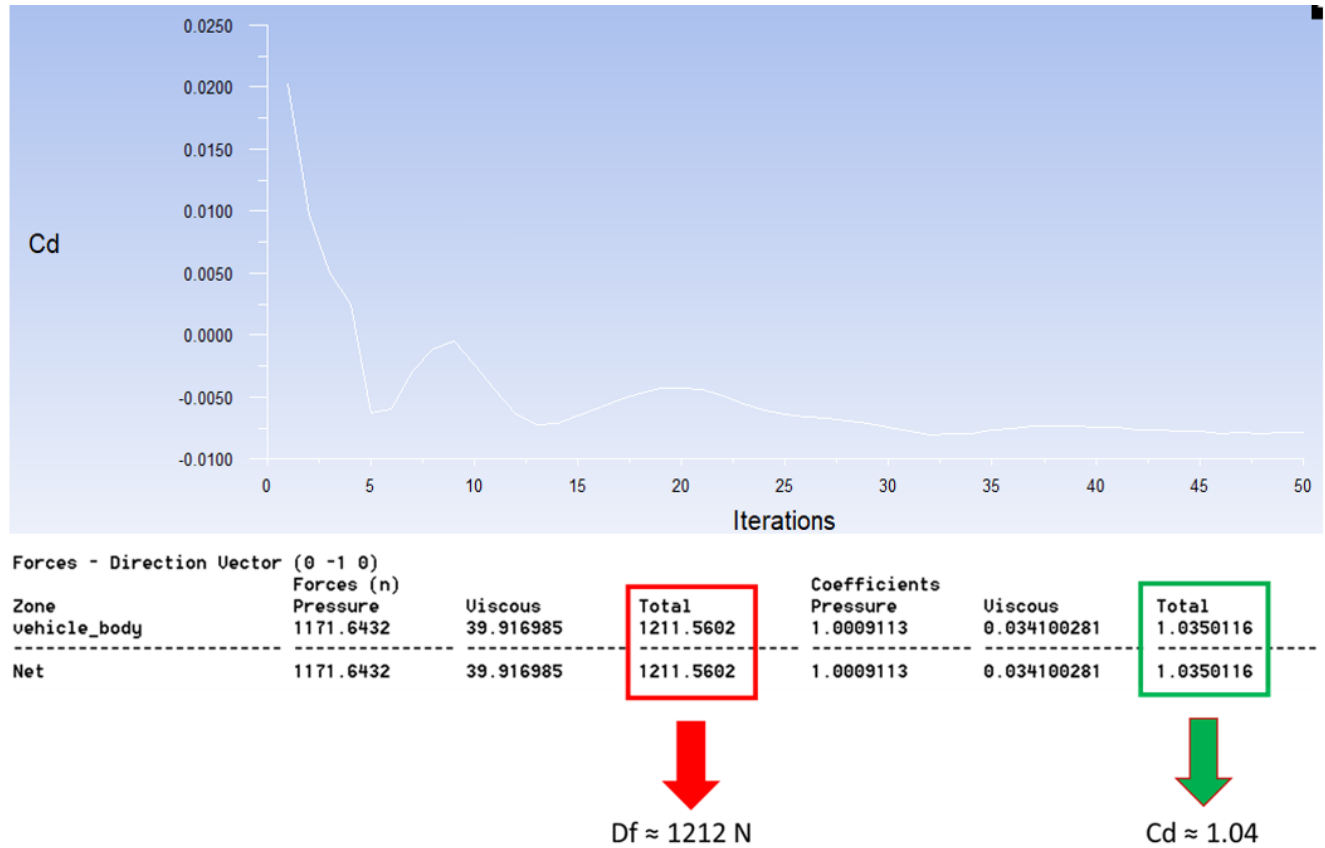

- With the $1^{\text {st }}$ deflector - only results
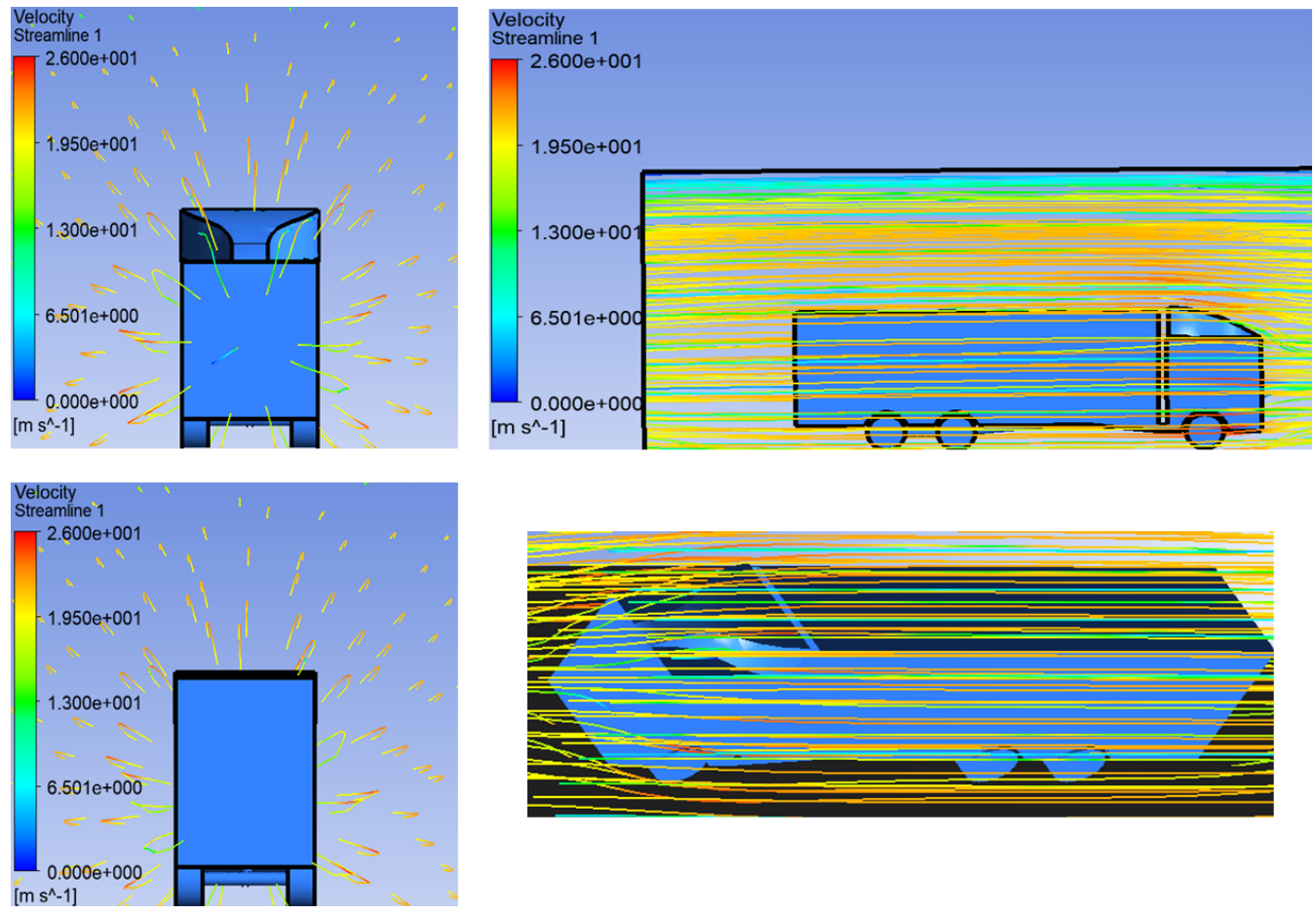

Figure 4. Velocity analysis for the first deflector 

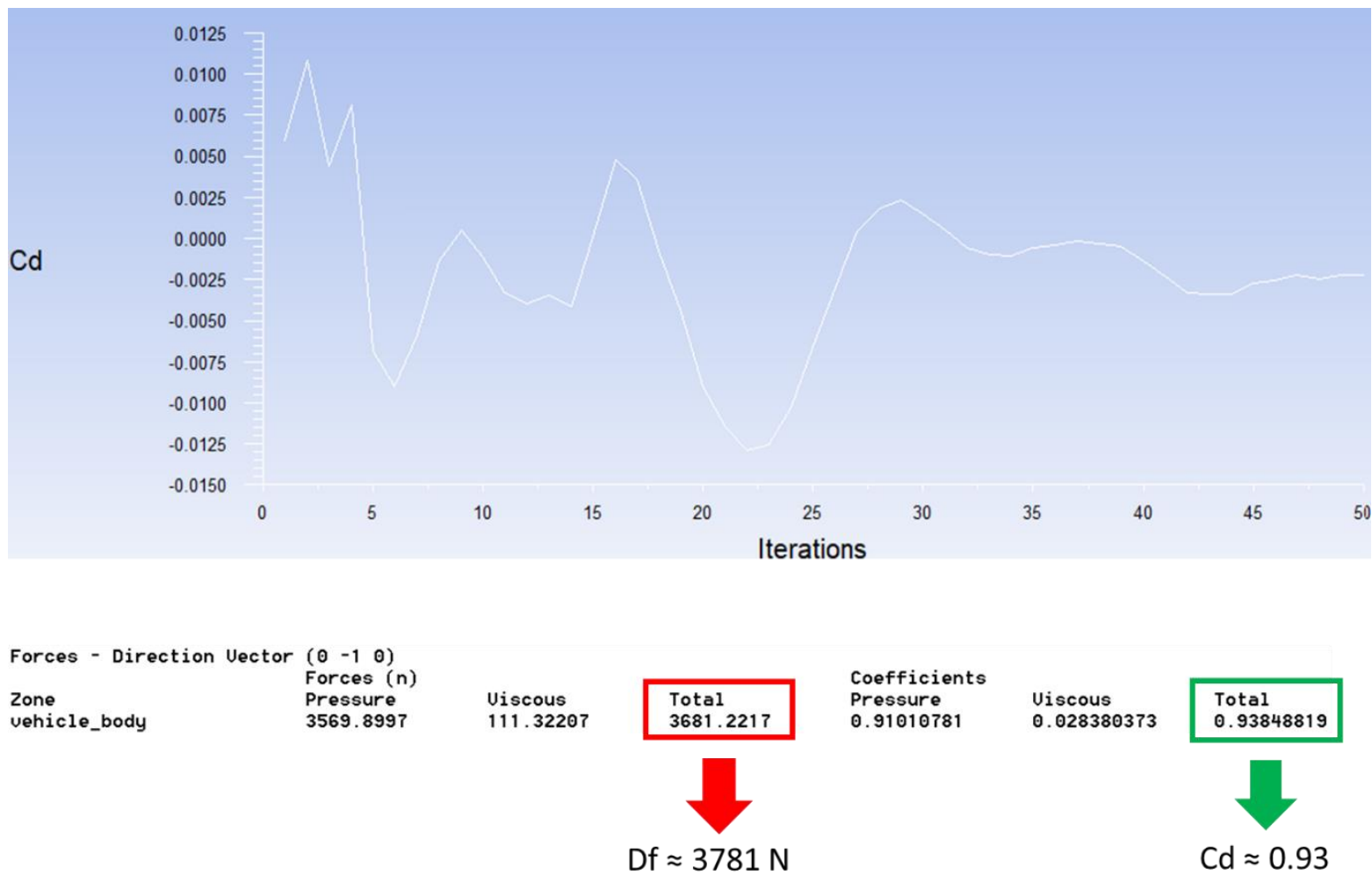

Figure 5. Analysis result for the first deflector

- With the $2^{\text {nd }}$ deflector - only results
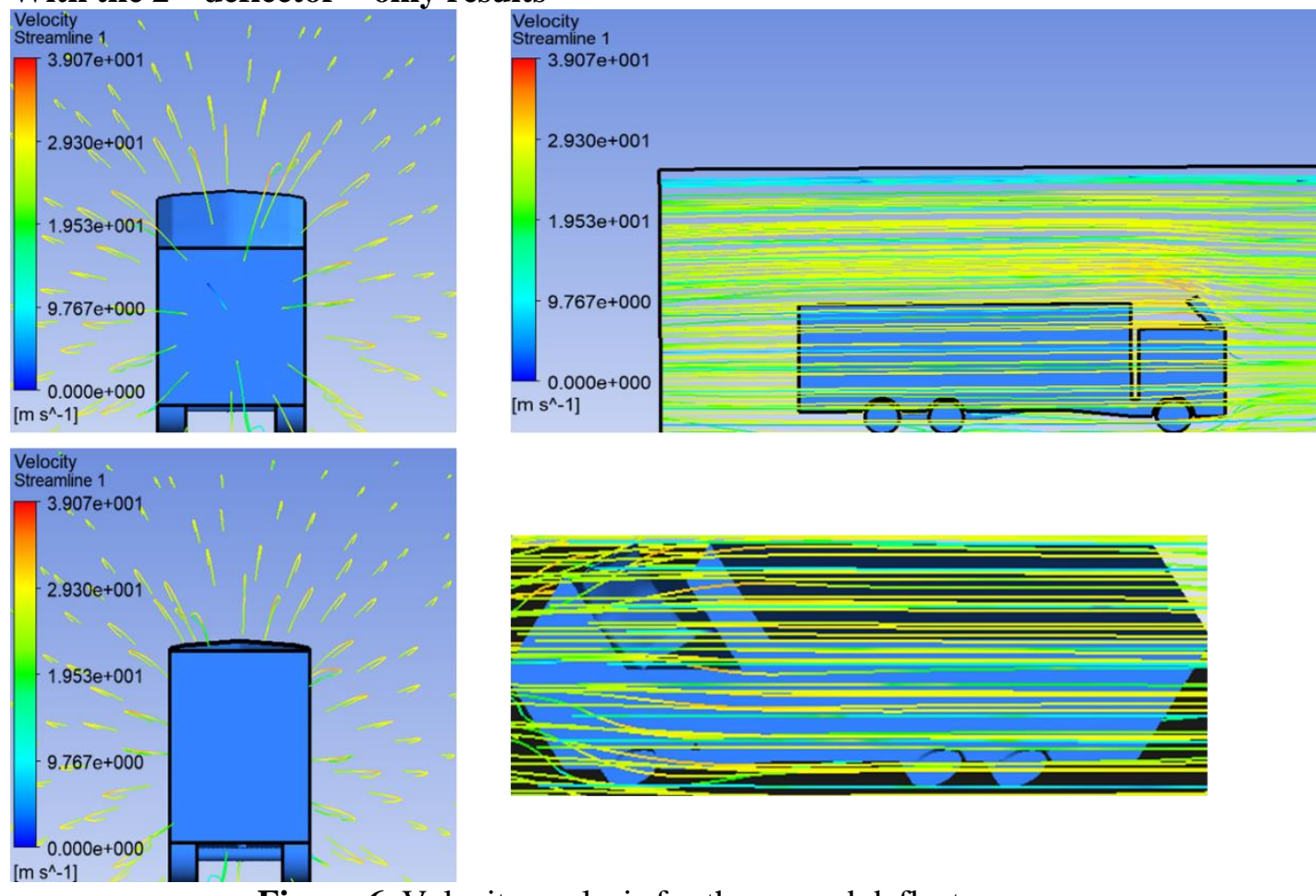

Figure 6. Velocity analysis for the second deflector 


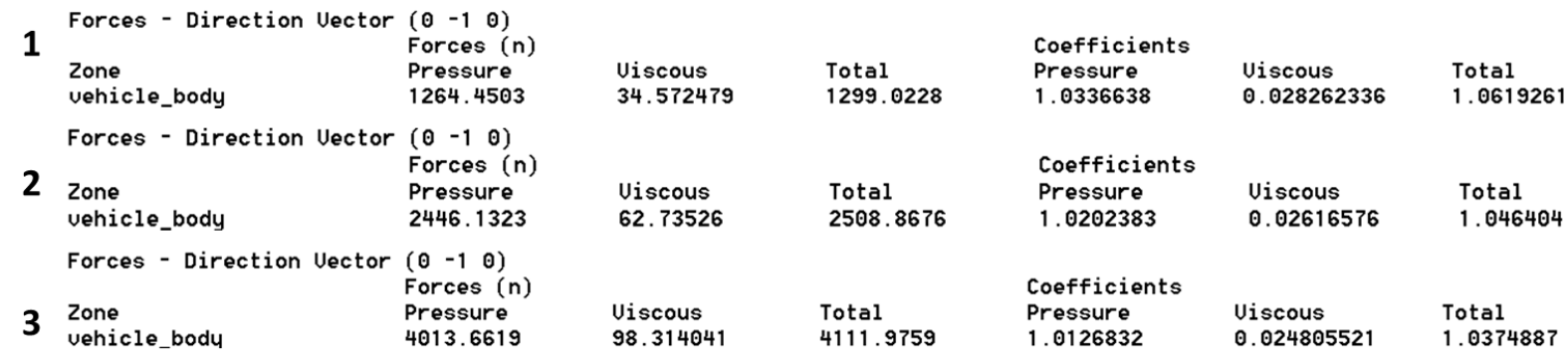

Figure 7. Analysis result for the second deflector

- With the $3^{\text {rd }}$ deflector - only results

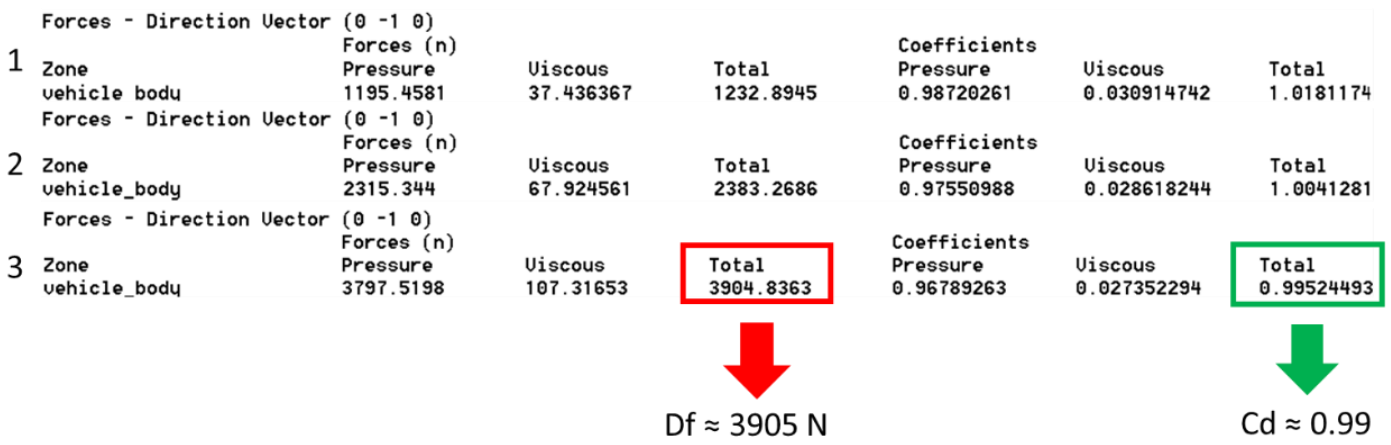

Figure 7. Analysis result for the third deflector

\section{Conclusions}

In this paper a practical study was performed which wanted to demonstrate the impact of a deflector geometry on the aerodynamics of a transport vehicle. In this sense, 3 cabin deflectors with simpler or more complex geometries have been designed that have or have not fulfilled their proposed purpose. Of all the geometries presented, the most efficient cabin deflector is the first one deflector.

I consider this deflector to be the most eficient due to the results obtained and presented. Even if the schematic model truck has a high coefficient of over 1.04, this cab deflector manages to reduce by up to $30 \%$ the effort made for forwarding. The air is guided without turbidity to the desired areas of the assembly. Thus the turbidity factor which increase the drag force is reduced to the lowest values. However, even in this case the aerodynamic coefficient can be improved by changing the first curve in the deflector section of the convex which increases the drag force into the concave one which would decrease the air turbidity and guide the air flows more smoothly. In conclusion, from the presented data can be extracted the premises of future research to optimize the solutions proposed in this paper.

\section{References}

[1] Abdellah Ait M., Justin F. and Rohan Y., "Aerodynamic Drag Reduction for a Generic Truck Using Geometrically Optimized Rear Cabin Bumps," Hindawi Publishing Corporation, Journal of Engineering, p. 14, 2015.

[2] Hariram A., Koch T., Mårdberg B.and Kyncl J. A., "A Study in Options to Improve Aerodynamic Profile of Heavy-Duty Vehicles in Europe," MDPI: Sustainability, vol. 11, no. 19, p. 23, 2019.

[3] MobilitateEu, "Designul aerodinamic al avioanelor și al trenurilor," [Online]. Available: https://mobilitate.eu/designul-aerodinamic-avioanelor-trenurilor/. [Accessed 1911 2020].

[4] Namazian Z., "Optimization of Geometry of a New Device to Reduce Aerodynamic Drag on a Heavy Vehicle," International Journal of Mechanical \& Mechatronics Engineering, 2016. 